\title{
SURVIVAL RELATED FACTORS IN GASTRECTOMY SPECIMENS. A STUDY OF 65 CASES IN DUHOK CITY - IRAQ
}

\author{
MOHAMMED RASHEED MOHAMMED, MBCHB, HD (General Surgery)* \\ ALAA HANI RAZIQ, MBCHB, FICMS (Pathology)**
}

Submitted 20 Dec 2020; accepted 6 Feb 2021

\begin{abstract}
Background: Gastric cancer is one of the commonest malignancies and one of the most common causes of cancer deaths worldwide. This study aims to investigate the survivalrelated factors in gastrectomy specimens.

Method: This is a cross-sectional retrospective study that included 65 gastrectomy specimens in Duhok City-Iraq over a period of 6 years from January 2014- November 2019.

The parameters sought included age, gender, histological type, grade, lymph node status, tumor size, resection margin status, and lymphovascular and perineural invasions. Patients were grouped for their ages with an interval of 10 years and pathological parameters were expressed in frequencies and percentages.

Results: The male to female ratio was 1.1:1, and the most affected age group was between 60-69 years. The intestinal type adenocarcinoma represented $64.61 \%$ of cases, and the remainders were of the diffuse type. The resection margins were tumor-free in $78.5 \%$ of cases, and $80 \%$ had a lymphovascular invasion. Perineural invasion was seen in $35.38 \%$ of the included patients. Only $16.92 \%$ of patients were negative for lymph node involvement, and the nodal status was N0: $16.9 \%, \mathrm{~N} 1: 58.5 \%, \mathrm{~N} 2: 18.5 \%$, and $\mathrm{N} 3: 6.1 \%$, and $66.15 \%$ of them fell in T3 category. The majority of patients had more than 4 adverse survival-related factors.

Conclusion: The present study showed that most of gastric carcinoma patients had multiple bad prognostic factors a fact that mostly correlated to their late presentation and a finding that indicates the gloomy outcome for patients at least in the near foreseen future unless a screening program is rapidly initiated.
\end{abstract}

Duhok Med J 2021; 15 (1): 58-68.

Keywords: Gastrectomy, Iraq, Survival Related Factors

S tomach carcinoma continues to be a major issue in oncology despite reducing its incidence globally ${ }^{1}$, and still, it ranks 5th among others 2 . Until recently, its prognosis is gloomy and comes second to colorectal cancer as a cause of death from gastrointestinal cancers worldwide1. Gastric adenocarcinoma is multifactorial, with the possible interaction between genetic and environmental factors. Among the most important causes are; smoking, alcohol, dietary factors, infection with $\mathrm{H}$. pylori, autoimmune gastritis, chronic atrophic gastritis, intestinal metaplasia, previous gastric surgeries, Peutz-Jeghers syndrome, Li-Fraumeni syndrome, and hereditary diffuse gastric cancer syndrome $\mathrm{e}^{3-6}$.

When all stages are combined, the 5 years survival still falls below $20 \%$. The best option for treating stomach cancer is surgical removal with the lymph nodes plus the consideration of chemotherapy and or radiotherapy, which may have a good impact on the outcome ${ }^{7}$. Although remarkable progress has been made in

\footnotetext{
* Assistant Lecturer, Department of Surgery, College of Medicine, University of Duhok, Kurdistan Region, Iraq ** **Professor, Department of pathology, College of Medicine, University of Duhok, Kurdistan Region, Iraq Correspondence author: Alaa H. Raziq, ala_hani@yahoo.com, Mobil+7504801310 https://doi.org/10.31386/dmj.2021.15.1.6
} 
gastric cancer treatment, gastrectomy with regional lymphadenectomy still remains the primary treatment for the resectable disease. Surgical resection alone with no pre-or postoperative treatment provides a five-year overall survival rate of approximately $20-30 \%{ }^{8,9}$.

Many factors affect the outcome of stomach adenocarcinoma. Knowledge about these factors enables us to assign the patient to a specific prognostic group and determine the most suitable therapeutic protocols to increase patients' survival and reduce the possible recurrence rate ${ }^{7}$.

Advancing age was found to have a negative impact on survival, while gender does not have such an effect in one Korean series ${ }^{10}$. In contrast, in another study, it was found that females with gastric carcinoma were significantly younger and had more signet ring carcinoma histology than males. Furthermore, females had significantly poorer outcomes among young patients with signet ring carcinoma $^{11}$.

The tumor stage is the most significant factor post-surgically, according to the International Union against Cancer/ American Joint Committee on Cancer (UICC/AJCC) $^{12,13}$.

Tumor size is an important determinant of survival. The five-year survival rate was $84.3 \%$ in $\mathrm{T} 1$ tumors, $64.8 \%$ in $\mathrm{T} 2$ tumors, $48.9 \%$ in $\mathrm{T} 3$ tumors, and $29.2 \%$ in $\mathrm{T} 4$ tumors, according to one series12. Survival rates vary according to the $\mathrm{T}$ and $\mathrm{N}$ stage, being around $85-90 \%$ in $\mathrm{T} 1$ tumors and around $15-20 \%$ in T4 tumors and node-positive patients ${ }^{14}$.

Lymph node metastasis has the most decisive influence on the prognosis of gastric cancer ${ }^{15}$.
According to one huge meta-analysis of 73 data, the diffuse type of gastric carcinoma has a worse prognosis than the intestinal type $^{16}$.

Other important factors that influence patients' survival include lymphovascular invasion, grade, resection type, and performance status ${ }^{8}, 9$. When both coexist, the lymphovascular and perineural invasion have a significant prognostic impact on disease-free survival and overall survival in patients with Stage II or III gastric cancer (17). Perineural invasion was found to be an independent prognostic factor (18). According to a multiple logistic regression model, depth of cancer invasion and lymphatic invasion were significantly correlated with lymph node metastases. Among the clinicopathological factors, depth of invasion and microscopically lymphatic invasion are important factors in predicting lymph node metastases. Thus, the ability to perform gastrectomy with dissection of lymph nodes represents a basic requirement for gastric cancer surgeons (15). The lymph node ratio is a predictor of survival for patients who underwent curative gastrectomy regardless of the number of lymph nodes examined. Thus, the lymph node ratio may be adopted as a new indicator for prognostic purposes 19.

Prognostic score based on age, tumor size, and grade forms an independent predictor of survival after gastrectomy ${ }^{2021}$. Involvement of the resection margins is another key prognostic ${ }^{22}$.

This study aims to identify the main prognostic factors affecting survival and recurrence of gastric adenocarcinoma. 


\section{METHODS}

This retrospective study included 65 cases of stomach adenocarcinoma in Duhok City from 2013-2019. Reports and slides were retrieved from many laboratories in Duhok. The patient privacy was maintained by giving a code for each patient. All the 65 cases had gastrectomy for stomach carcinoma. Patients were divided according to their gender and age groups using a 10 years interval. Then a search for all factors included in the reports and have relations to the prognosis was determined. These included age group, histological types, grade, resection margins involvement, lymphovascular invasion, perineural invasion, and lymph nodes status. The results of each variable were expressed in frequencies and percentages.

\section{RESULTS}

Figure 1 demonstrates the gender distribution of included patients, 31 females, and 34 males.

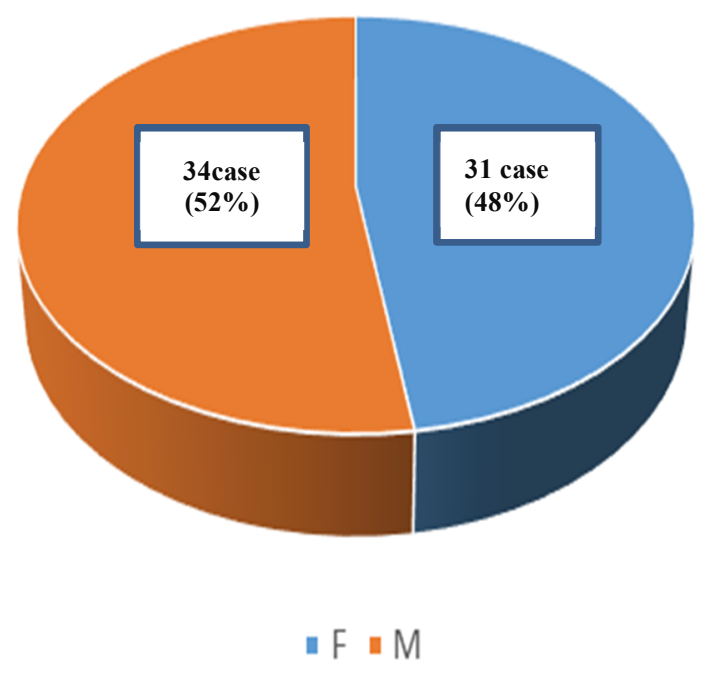

Figure 1: The gender distribution of the included patients.
The most affected age group ranges from 60-69 years, and figure 2 shows the age distribution of all the patients.

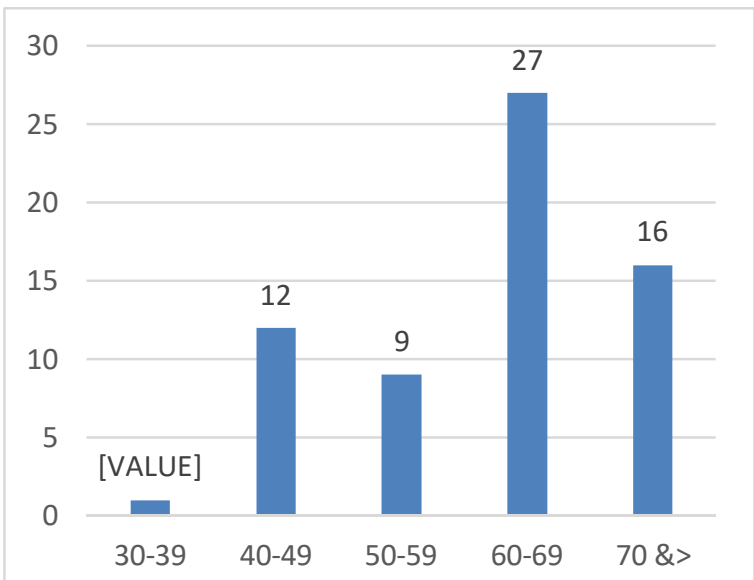

Figure 2: The age distribution of the included patients.

The intestinal type of gastric carcinoma was diagnosed in $42(64.61 \%)$ patients, and table 1 shows the histological types of gastric carcinoma.

\begin{tabular}{|c|c|c|}
\hline Histological type & No. & $\%$ \\
\hline Intestinal & 42 & 64.61 \\
\hline Diffuse & 21 & 32.31 \\
\hline Mucinous & 1 & 1.54 \\
\hline In-situ & 1 & 1.54 \\
\hline
\end{tabular}

Table 2: The histological grading of the 42 cases of the intestinal type adenocarcinoma.

\begin{tabular}{lcc}
\multicolumn{1}{c}{ Tumor grade } & No & \% \\
\hline Well differentiated & 2 & 4.76 \\
Moderately & 22 & 52.38 \\
differentiated & & \\
Poorly differentiated & 18 & 42.86 \\
\hline Total & $\mathbf{4 2}$ & $\mathbf{1 0 0}$ \\
\hline
\end{tabular}

Only $2(4.76 \%)$ cases out of the 42 cases were well-differentiated (Table 2). The resection margins were tumor-free in 51 (78.5\%) cases and involved by the tumors 
in the rest $14 \quad(21.5 \%)$ cases. Lymphovascular invasion was detected in $52(80 \%)$ of cases. Perineural invasion was detected in $23(35.38 \%)$ cases.

About the lymph node status table 3 shows that only $11(16.92 \%)$ cases had no lymph node involvement, and the rest of the patients have variable lymph node involvement.

\begin{tabular}{|c|c|c|c|c|}
\hline $\begin{array}{c}\text { Number } \\
\text { of LN } \\
\text { involved }\end{array}$ & $\begin{array}{c}\text { No. of } \\
\text { patients }\end{array}$ & $\%$ & $\begin{array}{l}\text { Nodal } \\
\text { status }\end{array}$ & $\%$ \\
\hline 0 & 11 & 16.92 & N0 & 16.9 \\
\hline 1 & 6 & 9.23 & \multirow{8}{*}{ N1 } & \multirow{8}{*}{58.5} \\
\hline 2 & 6 & 9.23 & & \\
\hline 3 & 7 & 10.76 & & \\
\hline 4 & 8 & 12.30 & & \\
\hline 5 & 8 & 12.30 & & \\
\hline 6 & 3 & 4.61 & & \\
\hline 7 & 3 & 4.61 & & \\
\hline 8 & 1 & 1.53 & & \\
\hline 9 & 1 & 1.53 & \multirow[t]{6}{*}{$\mathrm{N} 2$} & \multirow[t]{7}{*}{18.5} \\
\hline 10 & 2 & 3.07 & & \\
\hline 11 & 2 & 3.07 & & \\
\hline 12 & 1 & 1.53 & & \\
\hline 13 & 1 & 1.53 & & \\
\hline 14 & 1 & 1.53 & & \\
\hline 16 & 1 & 1.53 & \multirow{4}{*}{ N3 } & \\
\hline 17 & 1 & 1.53 & & \multirow{3}{*}{6.1} \\
\hline 18 & 1 & 1.53 & & \\
\hline 24 & 1 & 1.53 & & \\
\hline Total & 65 & 100 & & 100 \\
\hline
\end{tabular}

In consideration of the tumor size $(\mathrm{T})$ in the TNM staging system, $43(66.15 \%)$ patients fell in the T3 category (Table 4).
Table 4: The T variable in the pTNM staging.

\begin{tabular}{lll}
\hline T variable in TNM & \multicolumn{1}{c}{ No. } & \multicolumn{1}{c}{$\%$} \\
\hline T0 & 1 & 1.54 \\
T1 & 3 & 4.62 \\
T2 & 12 & 18.46 \\
T3 & 43 & 66.15 \\
T4 & 6 & 9.23 \\
\hline Total & $\mathbf{6 5}$ & $\mathbf{1 0 0}$ \\
\hline
\end{tabular}

When an age over fifty years and female gender are considered as poor prognostic factors, and with the consideration of other adverse factors (Diffuse histology, high grade, lymph node involvement, large tumor size, presence of lymphovascular invasion, perineural invasion, and resections margin involvement), the results of this study show that 15 patients had 4 adverse prognostic factors, 10 patients had 5 adverse factors and 17 patients had 6 adverse factors (Table 5).

\begin{tabular}{ccc}
\hline $\begin{array}{c}\text { Table 5: The number of adverse prognostic } \\
\text { factors in all the included patients. }\end{array}$ \\
$\begin{array}{c}\text { Number of } \\
\text { adverse } \\
\text { prognostic } \\
\text { factors }\end{array}$ & $\begin{array}{c}\text { Number of } \\
\text { patients }\end{array}$ & Percentage \\
\hline 1 & 1 & 1.53 \\
2 & 3 & 4.62 \\
3 & 7 & 10.77 \\
4 & 15 & 23.08 \\
5 & 10 & 15.39 \\
6 & 17 & 26.15 \\
7 & 7 & 10.77 \\
8 & 5 & 7.69 \\
9 & 0 & 0 \\
\hline Total & $\mathbf{6 5}$ & $\mathbf{1 0 0}$ \\
\hline
\end{tabular}




\section{DISCUSSION}

Gastric cancer, one of the commonest malignant tumors worldwide, causes thousands of deaths annually ${ }^{19,23,24,25}$ and represents the fifth most common cancer all over the world and the second leading cause of cancer mortality. There is marked geographical variation in its highest incidence in Japan, China, other East Asian countries, Eastern Europe, and South America. Over the past sixty years, there was a marked decline in the West incidence but an unfortunate increment in gastroesophageal ones ${ }^{26}$.

There is also significant variation in the outcome and survival rates, which reaches $70 \%$ in East Asian countries (including Japan) while remains low in most western countries despite the great advancement in the diagnosis and treatment with an overall survival rate of less than $30 \%{ }^{10,27}$.

The burden of gastric cancer is mostly bear by the developing countries, having more than $70 \%$ of the total world cases; most of these being in East Asia, which bear about $50 \%$ of total cases in the world ${ }^{2}{ }^{28}$. Extension of patients' lives after curative resection remains the consistent goal. Therefore, prognostic factors were studied extensively globally ${ }^{19}$.

Many studies confirmed the male predominance of gastric carcinoma $^{12,20,28,29}$, and this study is not an exception demonstrating a male to female ratio is $1.1: 1$.

The peak incidence in this series was in the 6th decade of life; this is similar to what was reported by Zeraati et al. in one Iranian series ${ }^{20}$ and higher than reports from Turkey, Kuwait, and Egypt ${ }^{12,26,29}$. While USA, Australia, China, Korea, and
UK, the peak incidence was in the 8th decade of life ${ }^{30,31,32,33,34,35}$.

Histologically, the intestinal type of gastric adenocarcinoma represented $64.61 \%$ of cases in this series, and this is in agreement with many other workers' reports $^{17,28,29}$.

Regarding grade of the intestinal type, only $2(4.76 \%)$ cases out of the 42 cases are well-differentiated, which is very similar to what was reported from Korea, Turkey, and Egypt ${ }^{10,12,29}$. The most likely explanation for this finding is that most cases of gastric carcinoma present lately and because of the absence of screening programs.

The resection margins in this work were tumor-free in $51(78.5 \%)$ cases and involved by the tumors in the rest 14 $(21.5 \%)$ cases; in a similar study done in North East Turkey, the resection margins were positive in $11.7 \%{ }^{36}$.

Unfortunately, the lymphovascular invasion was detected in $52(80 \%)$ of our cases, a much higher than what was reported from North East Turkey36 and Korea10. This fact could be attributed again to the late presentation in our patients.

Perineural invasion was linked to poor differentiation and advanced stage ${ }^{17}$, and in our study, the perineural invasion was detected in $23(35.38 \%)$ cases, and this is lower than what is reported from a multicenter meta-analysis which reported $40.9 \%{ }^{18}$.

Lymph node stage ( $\mathrm{N}$ stage) is one of the foremost prognostic factors ${ }^{37,38,39}$. It was considered as an independent prognostic factor $^{40}$. In this study, only 11 patients $(16.9 \%)$ were negative for lymph node involvement, and the lymph node stage 
was as follows N0: $16.9 \%, \mathrm{~N} 1: 58.5 \%, \mathrm{~N} 2$ : $18.5 \%$, and N3:6.1\%. Darwish et al reported a nodal stage of N0: $10.9 \%, \mathrm{~N} 1$ : $39.1 \%, \mathrm{~N} 2: 44.6 \%, \mathrm{~N} 3: 5.4 \%\left({ }^{29}\right)$ and Canyilmaz $\mathrm{E}$ et al reported a nodal status of N0:19.5\%, N1:25.3\%, N2 59:23\% N3A: $26.1 \%$, N3B: $6.2 \%{ }^{36}$. Data from one study in Iran showed that $55.8 \%$ of their patients had no lymph node involvement ${ }^{20}$, and from Korea $46.2 \%$ were negative for lymph node involvement ${ }^{10}$.

This study showed that $66.15 \%$ of cases had T3, which is an advanced $\mathrm{T}$ parameter in the staging system. Many other workers also demonstrated advancement in the $\mathrm{T}$ parameter $^{12,29,36}$.

The conclusion which could be made from this study is that still, stomach cancer presents in advanced stages with multiple bad prognostic factors. This fact necessitates introducing a screening program to diagnose cases in early stages with less adverse prognostic factors.

\section{CONFLICT OF INTEREST}

We - the authors of this research- declare that there is no conflict of interest

\section{ACKNOWLEDGMENT}

Great thanks and appreciation for Dr. Rafil Toma and Dr. Azad Mostafa - both are specialized pathologists in the University of Duhok- for their kind help in retrieving this research data.

\section{REFERENCES}

1. Ferro A, Peleteiro B, Malvezzi M, Bosetti C, Bertuccio P, Levi F. Worldwide trends in gastric cancer mortality (1980-2011), with predictions to 2015 , and incidence by subtype. European journal of cancer. 2014; 1; 50(7): 1330-44.

2. Ferlay J, Soerjomataram I, Dikshit R, Eser S, Mathers C, Rebelo M. Cancer incidence and mortality worldwide: sources, methods and major patterns in GLOBOCAN 2012. Int J Cancer. 2015; 136: 359-367.

3. Qiu MZ, Cai MY, Zhang DS, Wang ZQ, Wang DS, Li YH. Clinicopathological characteristics and prognostic analysis of Lauren classification in gastric adenocarcinoma in China. J Transl Med. 2013; 11:58.

4. Chou HH, Kuo CJ, Hsu JT, Chen TH, Lin CJ, Tseng JH. Clinicopathologic study of node-negative advanced gastric cancer and analysis of factors predicting its recurrence and prognosis. Am J Surg. 2013; 205:62330.

5. Lagergren $\mathrm{J}$, Bergström R, Lindgren A, Nyrén O. The role of tobacco, snuff and alcohol use in the aetiology of cancer of the oesophagus and gastric cardia. Int J Cancer. 2000;85:340-6.

6. Carr JS, Zafar SF, Saba N, Khuri FR, El-Rayes BF. Risk factors for rising incidence of esophageal and gastric cardia adenocarcinoma. J Gastrointest Cancer. 2013; 44:143-51.

7. Itaimi A, Baraket O, Triki W, Ayed K, Bouchouch S. Prognostic factors affecting survival and recurrence in gastric carcinoma. Cancer Rep Rev. 2018; Volume 2(6)

8. Cuschieri A, Weeden S, Fielding J, Bancewicz J, Craven J, Joypaul V, et al. Patient survival after D1 and D2 resections for gastric cancer: longterm results of the MRC randomized 
surgical trial. Surgical Co-operative Group. Br J Cancer. 1999; 79:152230.

9. Cunningham D, Allum WH, Stenning SP, Thompson JN, Van de Velde CJ, Nicolson $M$, et al; MAGIC Trial Participants.

Perioperative chemotherapy versus surgery alone for resectable gastroesophageal cancer. $\mathrm{N}$ Engl J Med. 2006; 355:11-20.

10. Alshehri A, Alanezi H, Kim BS. Prognosis factors of advanced gastric cancer according to sex and age. World Journal of Clinical Cases. 2020; 6;8(9): 1608.

11. Kim HW, Kim JH, Lim BJ, Kim H, Kim H, Park JJ. Sex disparity in gastric cancer: female sex is a poor prognostic factor for advanced gastric cancer. Annals of surgical oncology. 2016; 1; 23(13):4344-51.

12. Yaprak G, Tataroglu D, Dogan B, Pekyurek M. Prognostic factors for survival in patients with gastric cancer: Single-centre experience. Northern Clinics of Istanbul. 2020; 7(2): 146.

13. Zhang J, Zhou Y, Jiang K, Shen Z, Ye Y, Wang S. Evaluation of the seventh AJCC TNM staging system for gastric cancer: a meta-analysis of cohort studies. Tumour Biol. 2014; 35:852532.

14. Gunderson LL. Gastric cancerpatterns of relapse after surgical resection. Semin Radiat Oncol. 2002; 12:150-61.

15. Yokota $\mathrm{T}$, Ishiyama $\mathrm{S}$, Saito $\mathrm{T}$, Teshima S, Narushima Y, Murata K. Lymph node metastasis as a significant prognostic factor in gastric cancer: a multiple logistic regression analysis. Scandinavian journal of gastroenterology. 2004; 39(4):380-4.

16. Petrelli F, Berenato R, Turati L, Mennitto A, Steccanella F, Caporale M. Prognostic value of diffuse versus intestinal histotype in patients with gastric cancer: a systematic review and meta-analysis. Journal of gastrointestinal oncology. 2017; 8(1): 148.

17. Hwang JE, Hong JY, Kim JE, Shim HJ, Bae WK, Hwang EC. Prognostic significance of the concomitant existence of lymphovascular and perineural invasion in locally advanced gastric cancer patients who underwent curative gastrectomy and adjuvant chemotherapy. Japanese journal of clinical oncology. 2015; 45(6): 541-6.

18. Deng J, You Q, Gao Y, Yu Q, Zhao P, Zheng Y. Prognostic value of perineural invasion in gastric cancer: a systematic review and meta-analysis. PloS one. 2014; 9(2): e88907.

19. Hou Y, Wang X, Chen J. Prognostic significance of metastatic lymph node ratio: the lymph node ratio could be a prognostic indicator for patients with gastric cancer. World journal of surgical oncology. 2018; 16(1):198.

20. Zeraati H, Amiri Z. Estimating postoperative survival of gastric cancer patients and factors affecting it in Iran: Based on a TNM-7 Staging System. Acta Med Iran. 2016; 54(2): 114-8.

21. Lu J, Chen Y, Liu Y, Ding J, Piao Z, Liu W. Clinical significance of prognostic score based on age, tumor size, and grade in gastric cancer after 
gastrectomy. Cancer management and research. 2018; 10:4279.

22. Ohe H, Lee WY, Hong SW, Chang YG, Lee B. Prognostic value of the distance of proximal resection margin in patients who have undergone curative gastric cancer surgery. World journal of surgical oncology. 2014; 12(1): 296.

23. MD WCPD, Zheng R, Baade PD. Cancer statistics in China, 2015 [J]. Ca A Cancer J Clinicians. 2016; 66(2): 115-32.

24. Edge SB, Byrd DR, Compton CC, Fritz AG, Greene FL, Trotti A, editors. AJCC Cancer staging manual. $7^{\text {th }}$ ed. New York: Springer; 2010.

25. Jemal A, Siegel R, Ward E, Hao Y, $\mathrm{Xu}$ J, Michael J. Cancer statistics, 2009[J]. Ca A Cancer J Clinicians. 2009; 59(4): 225-49.

26. Al-Saleh K, El-Sherify M, Bedair A, Nazmy N, Elbasmi A, Hussein A. Clinicopathological Criteria and Prognostic Factors in Gastric Adenocarcinoma in Kuwait. Journal of Global Oncology. 2018; 4(4_supp1_2).

27. Karimi P, Islami F, Anandasabapathy S, Freedman ND, Kamangar F. Gastric cancer: descriptive epidemiology, risk factors, screening, and prevention. Cancer Epidemiol Biomarkers Prev. 2014; 23: 700-713.

28. Okuchukwu EH, Olayiwola OA. Epidemiology and clinic opathological characteristics of gastric cancer--the Nigerian setting in view. Niger $\mathrm{J}$ Med. 2015; 24:71-80.

29. Darwish H, Sakr A, Basaam W, Ghorab A. 10 years Experience in the Treatment of Gastric Cancer: A Single
Egyptian

Cancer

Center

(NEMROCK). Pan Arab Journal of Oncology. 2016; 9(3).

30. Lee HJ, Yang HK, Ahn YO. Gastric cancer in Korea. Gastric Cancer. 2002; 5: 177-182.

31. Yang L. Incidence and mortality of gastric cancer in China. World $\mathrm{J}$ Gastroenterol. 2006; 12(1): 17-20.

32. Jemal A, Siegel R, Ward E, Hao Y, $\mathrm{Xu}$ J, Murray T. Cancer Statistics. Cancer J Clin. 2008. 2008; 58;71-96.

33. Australian Institute of Health and Welfare (AIHW) and Australasian Association of Cancer Registries (AACR) 2001. Cancer survival in Australia, 2001. Part 1: National summary statistics. AIHW cat. no. CAN 13. Canberra: Australian Institute of Health and Welfare (Cancer Series No. 18), pages 20-23.

34. Cabebe EC, Mehta VK. Gastric cancer. Updated December 7, 2010 Available at http: // emedicine. medscape.com/article/278744overview. Acessed on January 16, 2011.

35. Cancer Statistics for the UK. Stomach cancer-UK incidence. Updated June 10, 2010. Available at http://info.cancerresearchuk.org/ cancerstats/ incidence. Accessed on January 16, 2011.

36. Canyilmaz E, Soydemir G, Serdar L, Uslu GH, Sahbaz A, Colak F. Evaluation of prognostic factors and survival results in gastric carcinoma: single center experience from Northeast Turkey. International journal of clinical and experimental medicine. 2014; 7(9):2656. 
37. Siewert JR, Böttcher K, Stein HJ. Relevant prognostic factors in gastric cancer: ten-year results of the German gastric cancer study. [J]. Ann Surg. 1998; 228(4):449-61.

38. Wu CW, Hsieh MC, Lo SS, Tsay SH, Lui WY, P'eng FK. Relation of number of positive lymph nodes to the prognosis of patients with primary gastric adenocarcinoma[J]. Gut. 1996; 38(4):525-7.
39. Yokota T, Kunii Y, Teshima S, Yamada Y, Saito T, Takahashi M. Significant prognostic factors in patients with early gastric cancer. [J]. Int Surg. 2000; 85(4): 286-90.

40. Chu X, Yang ZF. Impact on survival of the number of lymph nodes resected in patients with lymph nodenegative gastric cancer $[\mathrm{J}]$. World $\mathrm{J}$ Surg Oncol. 2015; 13(1): 1-8. 


\section{يوخته}

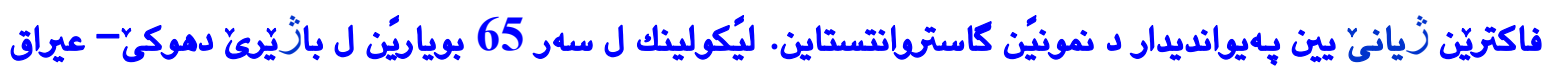

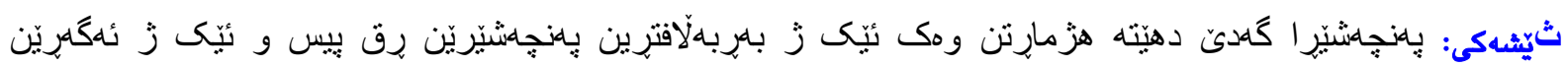

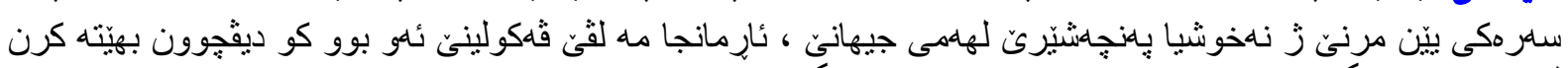

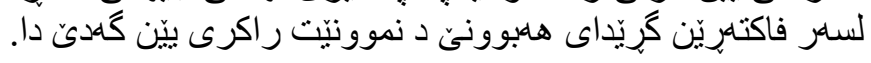

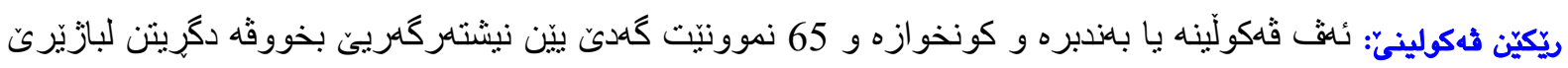

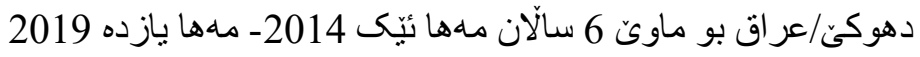

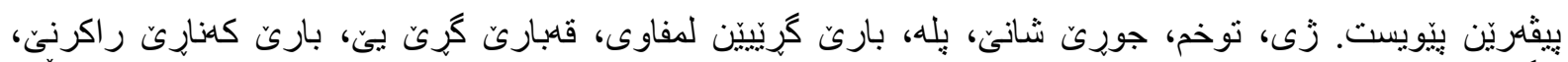

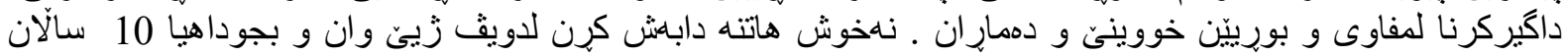

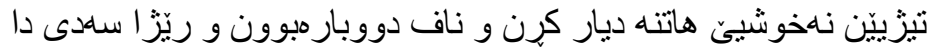

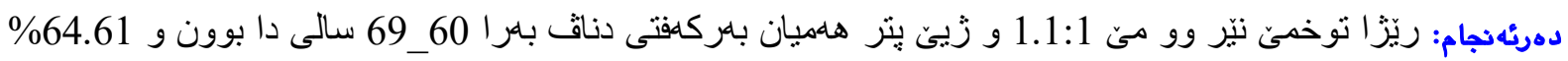

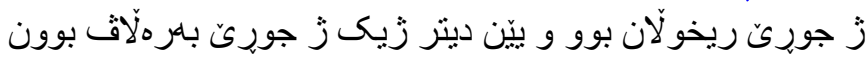

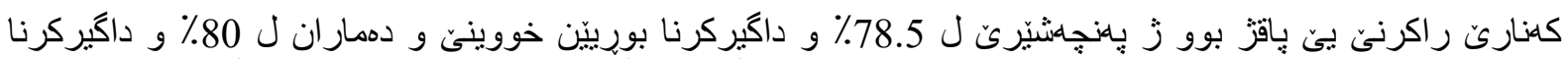

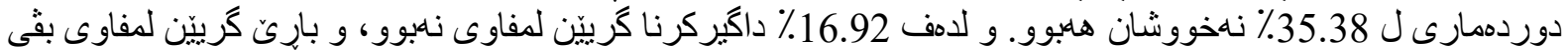

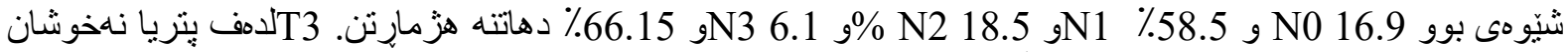

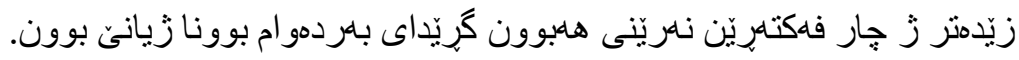

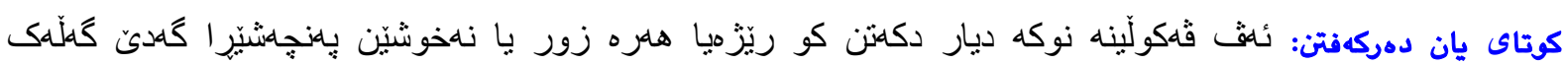

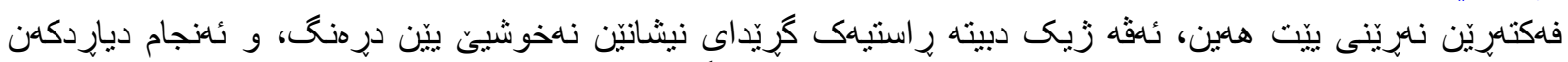

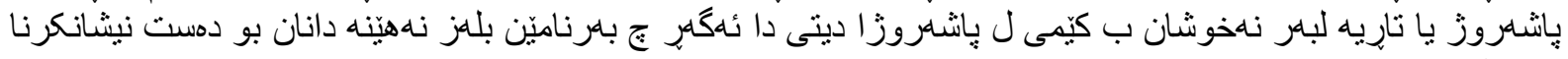

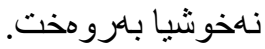




\section{الخلاصة}

عوامل البقاء على قيد الحياة ذات الصلة في عينات الجهاز الهضمي. دراسة 65 حالة في مدينة

$$
\text { دهوك - العراق عئات }
$$

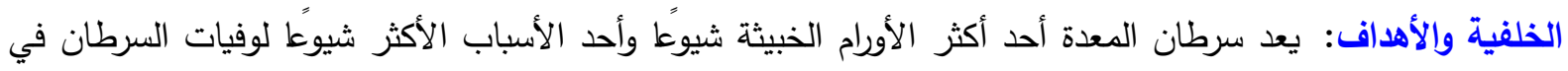
جميع أنحاء العالم. الهدف من هذه الدراسة هو التحقيق في العوامل المرتبطة بالبقاء في عينات استئصال المعدة.

طرق البحث: هذه دراسة مقطعية بأثر رجعي تضمنت 65 عينة استئصال معدة في مدينة دهوك - العراق على مدى 6 سنوات من كانون الثاني 2014 الى تثرين الثاني 2019

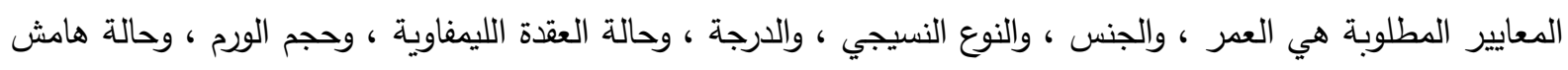

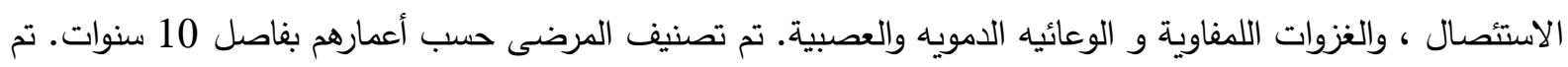
التعبير عن المعلمات المرضية في التكرارات والنسب المئوية.

النتائج: كانت نسبة الذكور إلى الإناث 1.1: 1 وكانت الفئة العمرية الأكثر تضررا بين 60-69 سنة. النوع المعوي يمثل

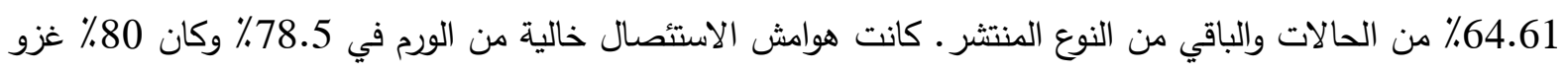

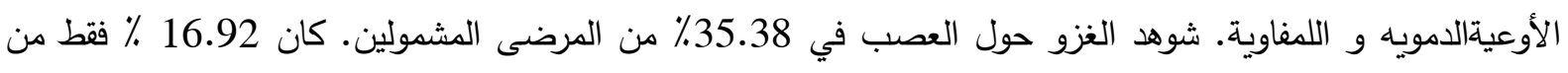

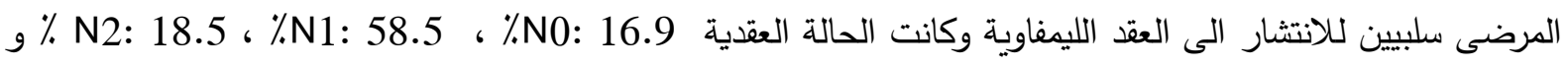

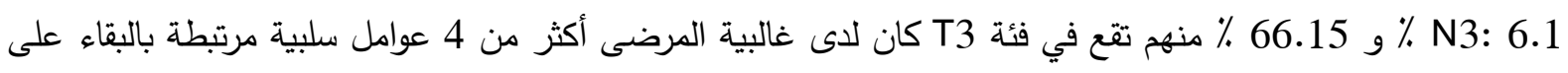
قيد الحياة.

الخلاصة:تُظهر الدراسة الحالية أن معظم مرضى سرطان المعدة لديهم عوامل تتبؤية سيئة متعددة ، وهي حقيقة ترتبط في الغالب بالعرض المتأخر والنتائج تثير إلى المستقبل القاتم للمرضى على العثى الأقل في المستقبل المنظور ما لم لم يبدأ برنامج

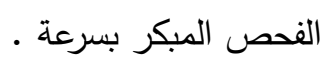

